SVU- International Journal of Veterinary Sciences, 4(2): 27-34, 2021.

Print ISSN: 2535-1826

\title{
Contribution on the size and morphology of subarcuate fossa in some mammals and its implications to phylogeny \\ Safwat Ali ${ }^{1}$, Abdelraheem Esmat ${ }^{1}$, Aef M. Erasha ${ }^{2}$
}

${ }^{1}$ Department of Anatomy and Embryology, Faculty of Veterinary Medicine, Minia University, ElMinia, Egypt

${ }^{2}$ Departments of Anatomy and Embryology, Faculty of Veterinary Medicine, University of Sadat City, Egypt

\section{Abstract}

The size of subarcuate fossa of six different mammals has been observed. Among the examined species; camel, dog, rabbit and rat show clear subarcuate structure, which was characterized by the shape of fossa, and could be easily measured by using endocast. In these species the parafloccular lobe of cerebellum is isolated from cranial cavity and engulfed by this fossa. However, in donkey, the fossa is unclear or absent. Studies have reported correlated relationship between the subarcuate fossa and the size of skull and certain parts of the cerebellum. The size of the subarcuate fossa is varying from absence of the fossa to large size fossa with its high contribution area of skull size. Dog has the largest subarcuate fossa among the examined species in this study followed by rabbit then camel, after that rat, very small in ruminants and nearly absent in equine. The study reveals the possibility of subarcuate fossa to determine the degree of evolution of the animals, based on variation of this fossa in closely related animals. This order does not follow any previous study in literatures that hypothesis correlation between the size of subarcuate fossa and the size of skull or animal size or even part of cerebellum which evolved in this fossa. The result of this paper supports the hypothesis of the correlation relationship between subarcuate fossa and phylogeny of the animals.

Keywords: subarcuate fossa, skull size, rat, ruminants, phylogeny.

DOI: 10.21608/svu.2021.60109.1103 Received: January 27, 2021 Accepted: May 15, 2021 Published: May 21, 2021 Corresponding Author: Safwat Ali: E-mail: asafawato@yahoo.com. Citation: Ali, 2021 Contribution on the size and morphology of subarcuate fossa in some mammals and its implications to phylogeny. SVU-IJVS 2021, 4(2):27-34.

Copyright: (C) Ali. This is an open access article distributed under the terms of the creative common attribution license, which permits unrestricted use, distribution and reproduction in any medium provided the original author and source is created.

Competing interest: The authors have declared that no competing interest exists.

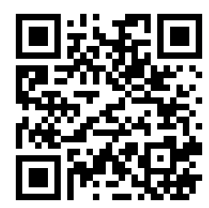




\section{INTRODUCTION}

Subarcuate fossa is located on the medial surface of the petrous part of the temporal bone, above and extended laterally to the internal acoustic meatus (Gannon et al., 1988; Spoor and Leakey, 1996). In many animals, the fossa is capacious and contains the petrosal lobule of the cerebellar paraflocculus (Didier, 1920; Gannon et al., 1988). On the other hand, the subarcuate fossa is faded in primates, for example the adult humans and great apes (Gannon et al., 1988; Spoor and Leakey, 1996). The subarcuate fossa is present in the newborn stage of the animals, but in the adult form of the same species it is faded. This fossa is closed by the progress of growth to form a canal called the petromastoid canal (Gannon et al., 1988). In humans and most of the other primates where the adult fossa is lacking, the immature fossa is covered by dura mater and filled with connective tissue, without the presence of any part of the cerebellum (Bast, 1932).

Sánchez-Villagra, (2002) explained that the subarcuate fossa size is hypoallometry in relation to skull size in marsupials. Other researches linked the presences of the subarcuate fossa or even its size to the presence and the size of petrosal lobe of cerebellum, suggesting their positive relationship through continuous expansion of the fossa size to its limit (Jeffery and Spoor, 2006).

The subarcuate fossa size may have evolutionary significance. Gannon and Jeffery, (1988) mentioned that subarcuate fossa/ paraflocculus of later primates tends to be smaller, while that of earlier primates is consistently large. Also, primates with larger subarcuate fossa may be attributed to the adaptation with certain physiological demand.
The inner ear region was used to understand the evolutionary relationships of animals by otologists on early 20th century. Gray (1907) stated that, the labyrinth must, of course, have some value when considering these relationships, just as have the teeth, the skeleton, and other parts of the body. This noticing led to many studies on the external surface of the petrosal part and cavities of the middle ear in mammals (Van Kampen, 1904; van der Klaauw, 1931; MacPhee, 1981), however, there is no broad phylogenetic study on the bony labyrinth in petrosal part

The petrosals are denser and more robust than other cranial parts, and the petrosal bone is the most conserved area in the fossil remains of the mammals. That is why, not only the ear region has physiological and phylogenetic significance in extant animals, but also the petrosal bone considered as a resource for recognition the phylogenetic relationships in extinct taxa. (Archibald, 1979; Quiroga, 1979; Miao, 1988).

This study on the petrosal part of the temporal bone was performed to investigate variation in different aspects of the subarcuate fossa in mammals, and its implication on a phylogenetic context.

\section{MATERIAL AND METHOD}

The specimens of camels and sheep were obtained after slaughtering from Minia slaughterhouse in Egypt. While the donkeys, dogs and rabbits were bought from farms and markets in Minia governorate, rats were obtained from faculty of agriculture, Minia University. The heads were dissected in the department of the anatomy and embryology, faculty of veterinary medicine, Minia university. The following mammalian species, representing six orders, were studied Carnivora- dogs (3 
males and 2 nonpregnant females), aging from 7 months to 3 years old; Artiodactylaone -humped camel (3 males and one nonpregnant female) aging from 5 to 6 years old; albino rats (4 males and one nonpregnant female), aging from 4 to 6 months old; New Zealand white rabbit (2 males and 2 nonpregnant females) aging from 3 to 5 months old; donkey (2 males and 1 nonpregnant female ) aging from 6 to 9 years old and Artiodactyla- Balady sheep (2 males and 1 nonpregnant females) aging from 2 to 3 years old.

For gross macroscopical anatomy, the heads were dissected parallel to median plans, and the brain was removed from each specimen to gain maximal exposure and extirpation of the petrosal part of temporal bone and subarcuate fossa.

The skull Processing for anatomical examination was done by following, firstly; the animal's skulls were skinned by using scalpel blade. After that, the muscles were removed by knives with different sizes. The scraping was done carefully not too hard to avoid scratch bone surfaces or break thin bone. Then electric saw was used to separate the skull into two equal halves in median plane. Finally, the brain tissue was removed from both halves. The bones were boiled with $\mathrm{NaOH}$ for 3-7 hours according to the animal skull size. The tissue fragments on the bone were removed by immersed them, in $95 \%$ gasoline until clean bones completely.

The morphology of the subarcuate fossa region was observed under light microscope (Axioskop 2 plus, Carl Zeiss light microscope - Germany) at 10-40 magnification. Plastic cast was added to the specimens to help in measurement of the subarcuate fossa volume. Twenty-seven casts were photographed (NIKON COOLPIX L29- Japan) and the measurements were done after magnification by using Imagej software (LOCI, University of Wisconsin - USA).

To estimate the volume of the subarcuate fossa, the skull was first oriented so that the arch of the superior semicircular canal (forming the ostium of the subarcuate fossa) was in the horizontal plane. The subarcuate fossa was filled with 5\% alcohol (to reduce surface tension, preventing air bubble formation within the subarcuate fossa) using a $10 \mu \mathrm{l}, 100 \mu 1$ or $1 \mathrm{ml}$ capacity Hamilton microsyringe. The fossa was filled with this solution up to the medial extent of the ostium formed by the superior semicircular canal, thus assuring a standard measure. In each specimen, the volume of both the left and right subarcuate fossa was measured, (mean $\pm \mathrm{SD}$ ).

\section{RESULTS}

In the examined species; camel, sheep, donkey, dog, rabbit and rat, only camel, dog, rabbit and rat show the clear subarcuate structure, which was characterized by the shape of fossa, and could be easily measured by using endocast. In these species the parafloccular lobe of cerebellum is isolated from cranial cavity and engulfed by this fossa. The other species, especially donkey, the fossa is absent.

\section{Donkey and sheep subarcuate fossa}

The subarcuate fossa of the donkey is absent. It is represented by unbounded depression (Fig. 1/A); this depression isn't isolated from cranial cavity. It is occupied by the most lateral part of the cerebellum. The subarcuate fossa of the sheep is a depression like (Fig. 1/B) In the sheep, the subarcuate fossa has no cavity, and doesn't engulf any specific cerebellar part. 

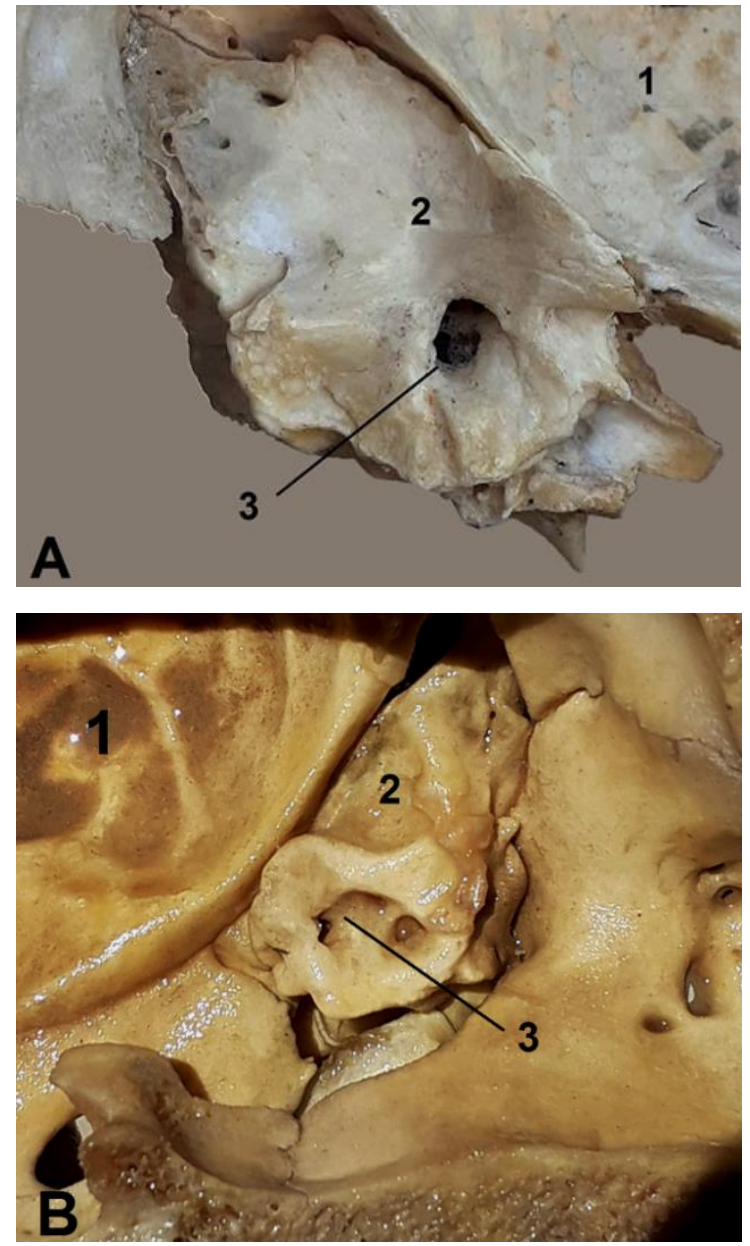

Fig. 1. Sagittal section in the donkey (a) and sheep (b) skull show the medial side of the petrosal part of temporal bone; 1 , cranial cavity; 2 , the area of the subarcuate fossa; 3 , internal acoustic meatus.

\section{Rabbit subarcuate fossa}

The subarcuate fossa of the rabbit (Fig. 2) is large but not the largest among the examined specimens. It is firmly attached with cerebellum and has the clear impression of the paraflocculus lobe of the cerebellar, which is lodged in the fossa. The fossa is cone shape and has walnuts appearance with narrow area at its contact with cranial cavity for nerve fiber stalk of paraflocculus lobe of the cerebellar. This narrow part is followed by broad base of about $7 \mathrm{~mm}$ breadth and most of its size is located caudally. It extends laterally with depth reach $(6 \pm 0.65$ $\mathrm{mm})$. The total volume of rabbit subarcuate fossa is about $\left(86 \pm 4.5 \mathrm{~mm}^{3}\right)$.

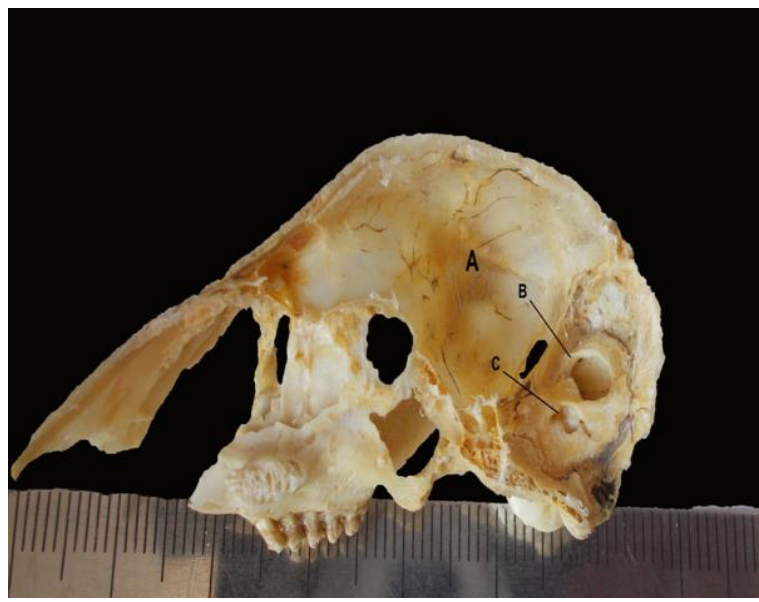

Fig. 2. Sagittal section in the rabbit skull; a, cranial cavity; b, subarcuate fossa; $c$, internal acoustic meatus.

\section{Rat subarcuate fossa}

The subarcuate fossa of the rat (Fig. 3) is the smallest through the examined species which have distinct subarcuate fossa. It has $\left(5 \pm 0.5 \mathrm{~mm}^{3}\right)$ volume. Its shape is oval, and it is directed rostrally and caudally with prominent round depression at its most extended part caudally. It has neck for nerve fiber stalk of paraflocculus lobe of the cerebellar. The impression of the parafloccular part of the cerebellum is not present.

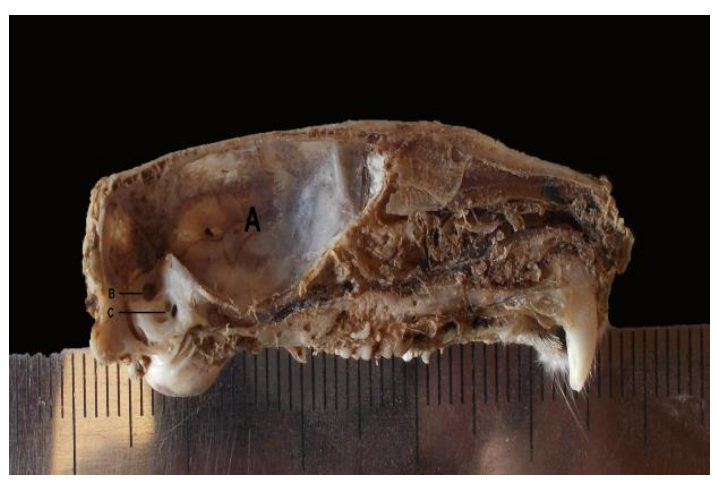

Fig. 3. Sagittal section in the rat skull; a, cranial cavity; b, subarcuate fossa; c, internal acoustic meatus. 


\section{Dog subarcuate fossa}

The subarcuate fossa is the largest in examined species (Fig. 4). Its volume is $\left(100 \pm 5.4 \mathrm{~mm}^{3}\right)$. its shape at most superficial part is half spherical and then it is continued deeply as rod shape. The impression of the parafloccular part of the cerebellum is present but not as clear as those present in rabbit, however other impression is clearly present doesn't seem to be formed by cerebellum. A spiral groove is started rostrally at most superficial part of the fossa and run on the wall of the fossa caudally and laterally for short distance, then directed downward abruptly. After this the groove continued running caudally with medial direction and ended in the most superficial part of subarcuate fossa ventrally.

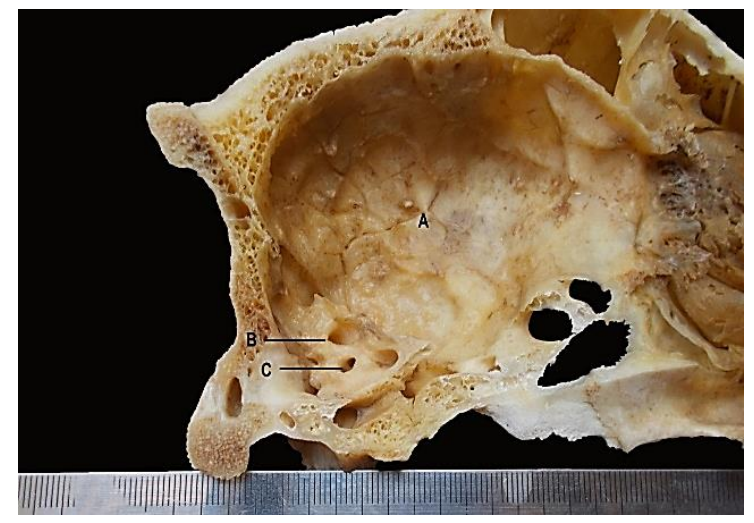

Fig. 4. Sagittal section in the dog skull; a, cranial cavity; b, subarcuate fossa; $c$, internal acoustic meatus.

\section{Camel subarcuate fossa}

The volume of the camel subarcuate (Fig. 5) fossa is $\left(70 \pm 3.1 \mathrm{~mm}^{3}\right)$, smaller than that of rabbit and dog. The paraflocculus lobe of the cerebellum leaves no impressions inside the fossa. The entrance of the fossa; the outer part is cone shape ended with constricted part; the neck then is then followed by slight expansion. Also, the petrosal lobule of cerebellar paraflocculus doesn't closely contact with the most inner part of the subarcuate fossa, which is locked by durra matter and connective tissue.

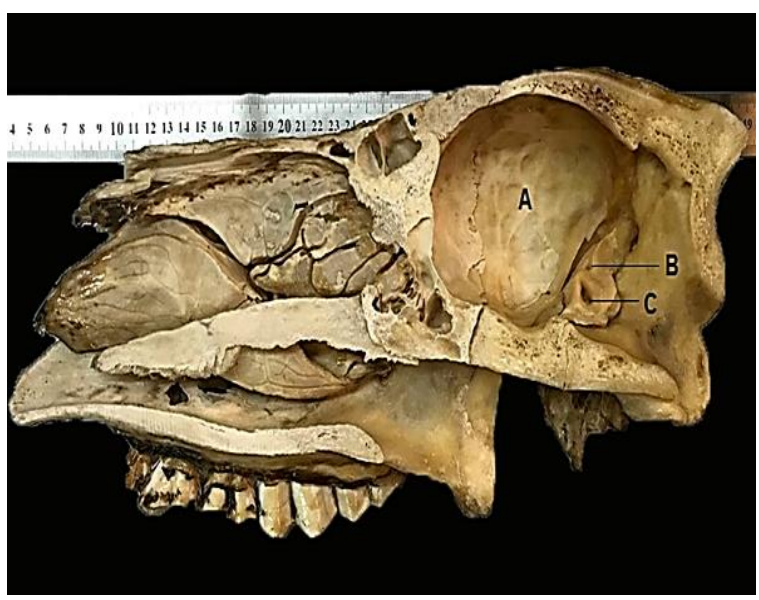

Fig. 5. Sagittal section in the camel skull; a, cranial cavity; b, subarcuate fossa; c, internal acoustic meatus.

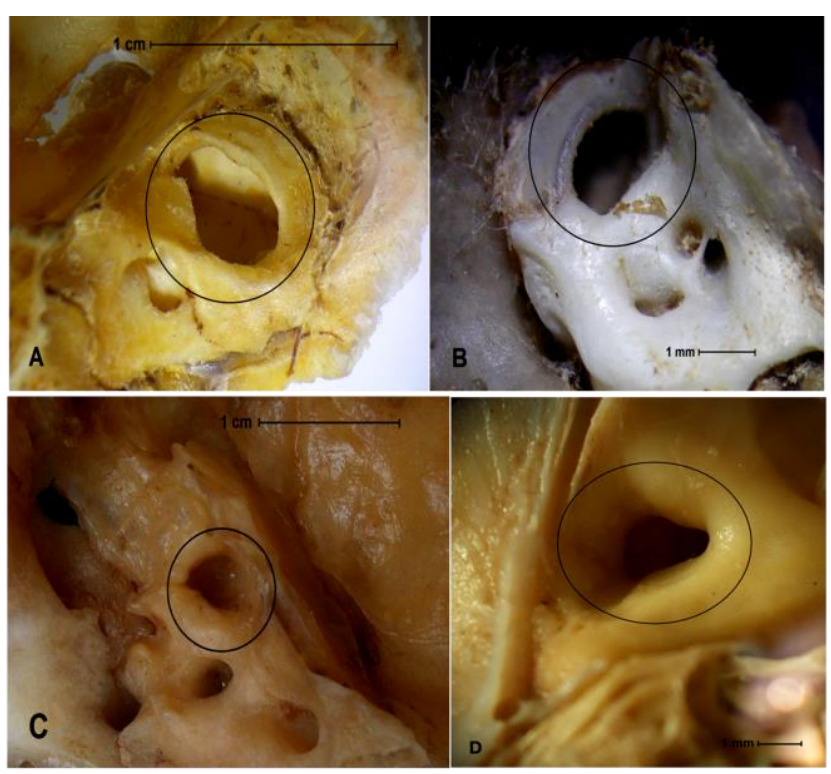

Fig. 6. Micro dissected subarcuate fossa. (a) subarcuate fossa of the rabbit, (b) subarcuate fossa of the rat, (c) subarcuate fossa of the dog, (d) subarcuate fossa of the camel.

\section{DISCUSSION}

The petrosal lobule of the cerebellum paraflocculus is one of lateral parts of the paleocerebellum. This part is thought to be involved in the coordination of axial muscles. The birds and reptiles have a small 
outbudding present in the paleocerebellar cortex. This structure has been described as homologous to the petrosal lobule of the cerebellum paraflocculus in the primate (Larsell, 1967). So, the petrosal lobule is considered as the oldest component of the cerebellar paraflocculus (Jansen, 1969). Among the mammals the folia of this lobe has great interspecific variations in number and size.

The mammalian paraflocculus petrosal lobe, which is situated in the subarcuate fossa, is the most lateral lobule of the cerebellar paraflocculus complex. The cerebellar paraflocculus considered the subarcuate fossa mirror, and in all species and specimens studied, it reflected the same form and volume of the fossa subarcuate. Our findings agreed with Gannon et al., (1988) in those cases where the subarcuate fossa is present, it is totally occupied by the paraflocculus petrosal lobe. The lobulation pattern of this lobe is, in rabbit and at a lower degree in dog, reflected by impressions on the bony walls of the fossa due to their intimate anatomical relationship, while in the camel and rat the impressions are not present. This degree of contact between the soft tissue represented by paraflocculus petrosal lobe could be used as an indication to the degree of development of the animal. We suggest that animals of clear paraflocculus petrosal lobe impressions like rabbit are earlier in phylogeny then come dog later than the other examined animal. .

The results referred that presence of large subarcuate fossa is not necessarily linked to presence of large cerebellar paraflocculus. According to SánchezVillagra, (2002) researches in ontogeny of a brain-skull interaction of the marsupial mammals declared that the fossa formed first without contribution of the cerebellar paraflocculus, which in turn fills the fossa first completely and then partially later in development. Also, he found a poor link between the dimension of this lobe and the subarcuate fossa in adults. SánchezVillagra (2002) reported that the subarcuate size is negatively allometric with respect to skull size. This later finding may be a result of applying the research on marsupials only.

The shape of subarcuate fossa is affected by the shape of cerebellum paraflocculus due to the intimate anatomical relationship during early stage of the development, but the petrosal lobe size has no direct influence on the size of the subarcuate fossa. However, the subarcuate fossa may be present in newborn and fetal animals, and it may be absent in adult of the same species. It gradually narrowed by bone and called petromastoid canal (Gannon et al., 1988). Some studies indicate that human fossa is present in fetal stage, with no relation to soft tissue; the cerebellum during its development (Streeter, 1917, 1918; Bast, 1930, 1932; Delattre and Fenart, 1959). During the human growth the fossa is covered by dura and filled by connective tissue not paraflocculus petrosal lobe (Bast, 1932), similar to that detected in other primate species lacking an adult fossa. The subarcuate fossa seems to be more linked with phylogeny of the animal and its developmental stage more than the function or other anatomical factors.

If a paraflocculus petrosal lobe invades the subarcuate fossa, it will expand to shape the lobule and will replace the dura matter and connective tissue. In other hand, it will disappear and fade if remains empty. However, initially develop of the subarcuate fossa may attribute as a genetically modified structure to preamble the lobule's growth (Jeffery and Spoor, 2006). So, existence and variation in the size may depend on degree of the bone and 
soft tissue interaction. Also, the genetics degree of expression accommodation to soft tissue of each species may be clues for phylogenic indication of this fossa.

The subarcuate fossa is present in earliest stage of animals and then regressed with aging. Also, it is housed and its persistence and expansion was linked with the most primitive part of paleocerebellum (Jansen, 1969), and our results revealed that the size of the subarcuate fossa is correlated with phylogeny and the degree of development of the animals; larger subarcuate fossa is correlated with more primitive animal.

\section{CONCLUSION}

The results of this study in conclusion suggest that subarcuate fossa has a phylogenetic indication, and the degree of the animal development may correlate with the impressions of paraflocculus petrosal lobe in subarcuate fossa. Also, the size of the subarcuate fossa is positively correlated to the degree of development of the animal. This hypothesis could be used to measure the degree of development of extinct animals; however, the most recent animal lack this fossa.

\section{ACKNOWLEDGMENTS}

The authors would like to thank anyone helped in this work by his experience or efforts in collecting samples, endocast.

\section{CONFLICT OF INTEREST}

The author declares that he does not have any conflict of interest.

\section{REFERENCES}

Archibald, J. D. 1979. Oldest known eutherian stapes and a marsupial petrosal bone from the Late Cretaceous of North America. Nature 281:669-670.

Bast TH (1932) Development of the otic capsule. I. Resorption of the cartilage in the canal portion of the otic capsule in human fetuses and its relation to the growth of the semicircular canals. Arch. Otolaryngol. 16: 19-38.

Bast, T.H., 1930. Ossification of the otic capsule in human fetuses. Contrib. Embryol. 21, 53e82.

Delattre, A., Fenart, R., 1959. Remarques sur la morphoge'ne'se des orifices de al face retro-tentoriale de I'os pe'treux humain. Bull. Mem. Soc. Anthropol. Paris 10, 326e356.

Didier G (1920) Contribution a I'Btude anatomique de la fossa subarcuata. Theses, Universite de Paris. Paris: Amedee Legrand.

Gannon, Patrick J., Avrim R. Eden, and Jeffrey T. Laitman. "The subarcuate fossa and cerebellum of extant primates: Comparative study of a skull-brain interface." American Journal of Physical Anthropology 77.2 (1988): 143-164.

Gray, A. A. 1907. The labyrinth of animals: including mammals, birds, reptiles and amphibians. Volume 1. J. and A. Churchill, London.

Jansen J (1969) On cerebellar evolution and organization from the point of view of a morphologist. In R Llinas (ed.): Neurobiology of Cerebellar 
Evolution and Development.

Chicago: American Medical Association, pp. 881-893.

Jeffery, Nathan, and Fred Spoor. "The primate subarcuate fossa and its relationship to the semicircular canals part I: prenatal growth." Journal of human evolution 51.5 (2006): 537-549.

Larsell 0 (1967) The Comparative Anatomy and Histology of the Cerebellum from Myxinoids through Birds. Vol. 1. Minneapolis: University of Minnesota Press.

MacPhee, R. D. E. 1981. Auditory regions of primates and eutherian insectivores: morphology, ontogeny, and character analysis; in F. S. Szalay (ed.), Contributions to Primatology, Volume 18. S. Krager, Basel, 282 pp.

Miao, D. 1988. Skull morphology of Lambdopsalis bulla (Mammalia, Multituberculata) and its implications to mammalian evolution. Contributions to Geology, University of Wyoming Special Paper 4:1-104.

Quiroga, J. C. 1979. The inner ear of two cynodonts (Reptilia - Therapsida) and some comments on the evolution of the inner ear from pelycosaurs to mammals. Gegenbauers Morphologisches Jahrbuch 2:178-190.

Sánchez-Villagra, Marcelo R. "The cerebellar paraflocculus and the subarcuate fossa inMonodelphis domestica and other marsupial mammals - ontogeny phylogeny of a brain-skull interaction." Acta Theriologica 47.1 (2002): 1-14.

Spoor, F., \& Leakey, M. (1996). Absence of the subarcuate fossa in cercopithecids. Journal of human evolution, 31(6), 569-575.

Streeter, G.L., 1917. The factors involved in the excavation of the cavities in the cartilaginous capsule of the ear in the human. Am. J. Anat. 22, 1e25.

Streeter, G.L., 1918. The histogenesis and growth of the otic capsule and its contained periotic tissue-spaces in the human. Contrib. Embryol. 7, $5 e 53$.

van der Klaauw, C. J. 1931. The auditory bulla in some fossil mammals: with a general introduction to this region of the skull. Bulletin of the American Museum of Natural History 67:1-352.

Van Kampen, P. N. 1904. De Tympanaalstreek van den Zoogdierschedel. P. N. Van Kampen and Zoon, Amsterdam, 378 pp. 